\title{
Appropriate care of the newborn: ethical dilemmas
}

\author{
Peter M Dunn University of Bristol, Department of Child Health, Southmead Hospital, Bristol
}

\section{Author's abstract}

Medical advances in newborn care have raised ethical dilemmas as to the level of care which is appropriate when an infant is severely damaged and incapable of a reasonable quality of life in the future. Some of the considerations, philosophical and practical, are discussed. It is concluded that within the framework of the law and after due consultation, decisions are best reached in privacy by the parents and their medical advisor and should be based on the perceived interests of the child.

Thirty to forty years ago when I was training as a doctor in the United Kingdom, medical ethics was not taught as a formal subject. At the time medical care of the newborn was fairly primitive. Babies were for the most part left in the charge of nursery nurses. The neonatal mortality was very high. Ethical dilemmas concerning the non-use of care for badly damaged infants just did not arise. Such babies were allowed to die. If one was to use the imagery of 'the slippery slope', then babies were already at or near the bottom. Ever since then they have been steadily crawling up the slope, contrary to what some critics would have us believe. For, as newborn care improved and babies gradually achieved patient status, doctors were obliged to face up to decisions about whether or not to attempt to salvage infants already known to be severely damaged. The development of neonatal intensive care twenty years ago made this need all the more urgent and essential. Meanwhile, the law stood to one side and gave little or no firm guidance in this difficult area. It was against this background that, in the late 1960 s, the following philosophy and practice was evolved to help me and my team meet the ethical dilemmas that we confronted almost daily in a large neonatal service of over 11,000 births a year. The argument ran as follows: In defending the patient's 'rights', whether it be to have prenatal diagnosis or to have a caesarean section or to submit to live-saving inter-

\section{Key words}

Newborn; ethical dilemmas; appropriate care. ventions, we must never lose sight of that most fundamental right of all, the right of choice, and the right not to have what doctors sometimes naively assume that our patients will or should want. The right to die, the right to death with dignity, concerns the right to refuse life-sustaining treatment that is a burden, that prolongs the act of dying and is not in the best interests of the patient.

As adults in sound mind, surely few would dispute our individual right in this matter. But suppose we have had a severe stroke, are paralysed, incontinent, unconscious and without hope of recovery; in such circumstances I would hope that my doctor and close relations would agree not to embark on longterm life support or, if it was already in use, that they would be prepared to withdraw it.

A somewhat similar situation exists in respect to the newborn infant who is unable to express an opinion, and whose interests have therefore to be represented by the parents and their medical advisors. These life-and-death decisions are very difficult and stressful. The parents are emotionally involved. They may have only a vague idea of the long-term outlook for their child and the implications for their family. They may wish, and indeed should be encouraged, to seek advice from others, such as relatives, friends or their family doctor, priest or solicitor. Likewise, the doctor would be wise to seek the views of other members of the health-care team and to obtain a second opinion from a senior colleague. Ultimately, though, the final decision should, I believe, be discussed and made in private by the parents and their doctor.

I am aware that a contrary view, held for instance by some in the USA, is that decisions in individual cases should be decided by ethical committees. However, such committees may be ponderous and perhaps insensitive, and may also tend to err sometimes on the side of continued life-support when this is not in the child's best interests. In addition, the wider discussion and publicity that often results may cause great distress to the already grief-stricken family. Certainly, though, in countries such as the USA with its medico-legal problems and constraints, ethical committees may help to protect the individual doctor and in these circumstances I can under- 
stand their value. Fortunately, this is not the situation in the United Kingdom.

The withholding of life-saving care may be considered in respect of three broad groups of newborn infants: those with severe malformations, those with severe hypoxic/traumatic brain damage, and those of extreme prematurity with major problems such as severe brain haemorrhage. In these circumstances the doctor should carefully explain the problem, the outlook and also the management options to the parents. Often he will not be seeking a decision from them, but rather trying as sensitively as possible to gain insight as to their wishes, should a life-threatening event arise. The factors that need to be taken into account include the probable longevity of the patient, with or without full medical care, and the quality of future life, taking into account the degree and permanence of the handicap and the amount of suffering which is likely to accompany it; this includes iatrogenic pain and distress in consequence of the need for repeated surgery. At the end of the day, an experienced doctor should hope to know in advance and take into account the parents' likely response, if and when he advises against the use of intensive care. While the impact of the child's suffering and disability on the family cannot be ignored, the decision must be based on the interests of the child. I always try myself to take the initiative in advising the withholding of intensive care, and thus spare the parents the stress and burden of first voicing the decision. If they don't agree, as sometimes happens, then I respect their wishes and continue the use of full life-support.

On other occasions, in contrast, the doctor may recommend intensive care or an operation which the parents then decline. When this happens I ask myself the following five questions:

Do the parents understand the clinical condition and prognosis of their child?

Do they wish to, or should they, consult others before finally making up their minds?

Do they require more time?

Is their decision a loving, caring one made in the best interests of their child?

And finally: Is their decision a reasonable one and, if in doubt, is it so unreasonable as to request them to seek other medical advice or for me to request that the child be taken into care under the protection of the courts?

There is one other point I would like to make: in giving advice in the area of ethical dilemmas, doctors must be careful not to impose their own cultural and religious prejudices on those whose beliefs and practices may be different from their own, bearing in mind though, of course, the requirements of the law of the land.

In fact, in 35 years' practice with newborn infants, I can only recollect one instance when the parents of a child in my care refused potentially life-saving treatment for their baby - an exchange transfusion for severe jaundice. It was against the parents' religious beliefs. Legal permission was sought and granted to override their objections. I am still uncertain as to whether this action was ethically correct, even if it was medically justified.

The personal qualities required by doctors who try to help parents to reach acceptable decisions in these ethical dilemmas are compassion, humility and courage. Doctors must be prepared to accept that they will occasionally make mistakes and they must be prepared to live with their doubts. As that great physician William Osler wrote:

'Errors of judgement must occur in an art which consists largely of balancing probabilities.'

Thus, it is inevitable that we will wonder from time to time as to the correctness of some of our decisions. These doubts we must be prepared to shoulder. It is part of the job. But, in order to spare parents the unbearable burden of these same doubts, it is necessary sometimes to give our views and advice with greater firmness and conviction than we may feel. In appropriate circumstances this medical paternalism is, in my view, a part of good doctoring.

In October 1990 the judiciary in the United Kingdom ruled on the quality of life issue in respect of the medical management of minors (1), a judgement that has been recently confirmed (2): The child in question, Baby $\mathrm{J}$, was a ward of court. $\mathrm{He}$ was an extremely premature infant, weighing $1.1 \mathrm{~kg}$ at birth, who, at the age of five months was considered to be severely brain-damaged, blind and deaf. Artificial ventilation was required from time to time to keep him alive. Both his parents and doctors wished to be permitted to withhold ventilation. The Official Solicitor submitted that, whatever the pain or the quality of life thereafter, life-sustaining treatment must never be withheld. On 19th October, the Court of Appeal, headed by Lord Donaldson, Master of the Rolls, rejected this absolutist approach and ruled that, while doctors and parents may not undertake actions whose purpose is to end life, they may, in appropriate circumstances, use drugs to relieve pain and distress, even though their use may advance the time of death. Furthermore, potentially life-prolonging interventions may be withheld when it is the considered medical and parental opinion that the future quality of life would be such that the disabled child would himself consider such a course to be in his or her best interests.

This decision is, of course, of immense importance in that at last the law has recognised the need for the availability of compassionate solutions to some of these difficult dilemmas. As Lord Donaldson said in his judgement:

'Doctors nowadays recognise that their function is not a limited technical one of repairing or servicing a 
body. They are treating people in a real life context. This at once enhances the contribution which the court or parents can make towards reaching the best possible decision in all the circumstances... . People have an amazing adaptability. But in the end there will be cases in which the answer must be that it is not in the interests of the child to subject it to treatment which will cause increased suffering and produce no commensurate benefit, giving the fullest possible weight to the child's and mankind's desire to survive.'
$A$ version of this paper was given at the 1st International Congress of Perinatal Medicine, Tokyo, 8th November 1991.

\section{References}

(1) Donaldson L J, Re J (a minor) 1990. 3 All ER, 930, pages 934-938.

(2) Re J (a minor) (Medical treatment): Court of Appeal. (Donaldson M R, Balcombe L J, Leggatt L J) 1992 Jun 10. 